\title{
Problems and Suggestions on Reform of Teacher Qualification Examination under the Background of National Unified Examination
}

\author{
Sufen $\mathrm{XU}^{*}$ \\ Psychology and Education Science College \\ Zaozhuang University \\ Zaozhuang, China \\ *Corresponding author
}

\author{
Yun WANG \\ Zaozhuang Experimental School \\ Zaozhuang, China
}

\begin{abstract}
Under the background of the national unified examination of teacher qualification certificate, the problems existing in the reform of teacher qualification certificate examination in China are mainly two aspects. Firstly, the differences between non-normal professional examinees and normal professional examinees are ignored, and secondly, the process assessment of teacher quality is ignored. The foreign advanced experience in the development of the teacher certification system includes: first, the teacher qualification is classified carefully and has distinct functions. Secondly, the teachers' qualification has paid attention to the process evaluation. Third, teacher certification focuses on professionalism and practice. Therefore, it is suggested that China should build an "open" education system for teachers based on "professionalism". Refine the evaluation standards of each link, improve the reliability of appraisers, and improve the quality of "national examination"; Rich certification materials, the establishment of authenticity and practicality of the combination of archives bag certification system.
\end{abstract}

Keywords-Teacher certification; National examination; Process assessment; Practical

\section{INTRODUCTION}

Teacher certification is the "threshold" for teachers to enter the profession. Since 2016, the teacher qualification certificate has been subject to the national unified examination. For normal students and non-normal students, to be engaged in the teaching profession, the teacher qualification certificate must be obtained by taking the national unified examination. The establishment of vocational access system has always been a common practice in the world. The certification system is the result of the professional development, as well as the manifestation of social division of labor and social management progress. The teacher qualification certificate system is the key link of teacher professional admittance and the product of teacher professional professionalization development. The establishment of a perfect teacher professional admittance system is the development direction of education in China.

The reform has a great impact on college students, both for normal majors and non-normal majors. Whether for undergraduate students or junior college students, the reform has aroused the general attention of college students. Before the reform of the teacher qualification examination system, normal students only need to pass the education, psychology courses and the corresponding mandarin level certificate to get the teacher qualification certificate directly, and after the reform, they have to take the national unified examination to get the qualification certificate. These reforms force the normal university students to pay more attention to the teacher qualification examination. Driven by the publicity of some social training institutions, a considerable number of non-normal professional college students also blindly signed up for the training and examination of teacher qualification certificate, hoping to increase a choice for future employment through obtaining teacher qualification certificate without considering its practical applicability.

In the past two years, teacher qualification examination training has been surging, the market "just needs" has been expanding rapidly, and various social examination training institutions have rushed into the teacher qualification examination training market and their qualifications, teachers and so on, are mixed, and these are directly affecting college students.

The reform of teacher certification has already attracted the attention and attention of college students, and caused the agitation of social training institutions. Only the university itself seems to be "indifferent", and has not made effective reform and response to the reform of teacher certification system so far, and its lag has been very obvious. At present, colleges and universities have lagged behind the current needs in the curriculum setting of the major of normal education, the setting of the elective courses of the class education, the content system of the class education, the teaching method and the training mode, and must carry out corresponding reforms.

\section{PROBLEMS EXISTING IN THE REFORM OF TEACHER QUALIFICATION EXAMINATION IN CHINA}

\section{A. Ignore the Difference between Non-normal Professional Students and Normal Professional Students}

In the kingdom of teacher certification exam system design, has neglected the normal education to cultivate students' "professional" characteristics, for both normal class 
specialty test is normal survival should examine, all use the same qualifications screening, exam content and evaluation system, an examinee both from the students of normal colleges and universities, students have also come from the normal colleges and universities or graduate years of social examinee, neglect or ignore an examinee of in-service training before "professional" cultivation and "non-professional" difference.

The problem of "fairness" arises from the competition between normal and non-normal graduates. As a "prepared teacher", normal students need to be trained according to basic education, which has obvious "specificity". And teachers' qualification system of "all living things equality" actually ignore the specificity, so that the students do during the period of learning to be "zero", and triggered a form of "fair" to cover "essence" unfair problem - and can be trained in the examination of the cover of normal education attainment and the lack of real education ability, it is difficult to guarantee its corresponding education faith and responsibility, education, knowledge and ability, easy to get certificate is an examinee implementation of professional teachers "pseudo growth". So-called "pseudo growth" teachers in the process of professional development seems to have as a qualified teacher or excellent teacher's qualification, but in fact only have some of the surface features of a teacher or a good teacher, the teacher's professional knowledge, professional skills and professional emotional in whole or in part did not meet the requirements of qualified teachers or excellent teacher, did not happen "fundamental change". [1] it can be seen that the defects in the design of the examination system inevitably hurt the teacher certification system itself and hurt the scientific development of the teacher team.

\section{B. Neglect of the Process of Teacher Quality Assessment}

Non-normal students have not received the professional training and training of teacher education before taking the national examination, and they do not have the preconditioned training and experience for at least 4 years on the teachers' professional candidates. Whether it is a pre-service teacher training institution or a normal student, it is easy to directly translate the result of "national examination" into the judgment standard of pre-service teacher professional development, and "education" is reduced from the fundamental purpose of teacher education training to the subordinate of "national examination". In the training stage of in-service teachers, there should be some "education" links, such as teachers' professional spirit, professional concept and professional ability, which need long-term knowledge accumulation and practical experience. If we ignore these "process" links blindly and ignore the basic and necessary training of pre-service teachers, the overall quality of teachers will inevitably be seriously damaged. [2] the current interview time is short, the content is little, and the evaluation criteria are only formal. If continue to use this way to judge an examinee practical education teaching ability, will inevitably lead to more sat through the training of all kinds of the interviews have some fixed routine type of interview skills, only see the interview technique is easy to make judges sat "gorgeous" appearance, and ignore the actual education teaching ability of an examinee accurate assessment.
III. FOREIGN ADVANCED EXPERIENCE IN THE DEVELOPMENT OF TEACHER CERTIFICATION SYSTEM

\section{A. The Teacher Qualification Classification is Fine, the Function is Clear}

In terms of the classification of teacher certification, the United States is the most diverse and well organized. American states classify teacher certificates from the top level into two categories: ordinary and special. Ordinary teacher certificates are classified according to age, function and rank. According to age, it is divided into four learning stages: infancy, childhood, adolescence and youth. [3] this is different from the general classification of learning stages in China. It better reflects the progressive principle of teaching and the order of students' physical and mental development.

From the perspective of functional division, the United States is divided into four categories: general education subject certificate, special education certificate, school service certificate and school management certificate. [4] it differentiates teaching and management. It is called "specialized in the field". The classification of functions not only gives full play to the teachers' own professional ability, but also facilitates their refined management and professional training.

\section{B. The Acquisition of Teacher Qualifications Focuses on Process Evaluation}

In Japan, teacher certificates are called teacher licenses. There are three types of general, temporary and special permits. In July 2006, the consultation report of Japan central committee of education committee on teacher training and qualification certificate system stipulated that the validity period of teacher qualification certificate was 10 years, and the teacher qualification certificate should be re-evaluated after the deadline. [5] Temporary license is mainly for teaching assistants, with duration of 3 years. It can only be used in Dudaofu County where certificates are granted. [6] the new special license is an extension of the temporary license, which is mainly targeted at those who have the front-line teaching work experience and pass the teacher personnel examination, and the period of validity is slightly longer than the temporary license, which is 3-5 years. It can be seen that the qualification recognition of Japanese teacher certificates is hierarchical and presents a multi-dimensional model of three types and three levels, which facilitates the refinement of the management of teachers.

The education staff dispensation act also gives a detailed description of the minimum credits and required courses required to obtain various teacher certificates. Compulsory subjects mainly include general education subjects, subject education professional subjects and teacher skills professional subjects. Among them, education subjects are divided into humanities, social and natural sciences. A minimum of 59 credits will be earned for the specialized teacher's license and the compulsory subject under the first-level teacher's license; the credit of compulsory subjects for the secondary teacher's license shall be at least 30 credits. [7] It can be seen that the recognition and management of teacher qualifications in Japan attaches great importance to the process evaluation and 
the unification of theory and practice.

\section{Teacher Certification Focuses on Professionalism and Practicality}

In Germany, the teacher professions belongs to the category of local civil servants, so the assessment of teacher qualifications is responsible by each state, especially strict, and pay great attention to professionalism and practice. The teacher qualification of primary and secondary school should be obtained after the applicant has received the professional study of higher school and has passed the national exam twice. First of all, students need to study in a university for 3-5 years, and the courses mainly include professional teaching, education science and school practice. Only those who pass the first national examination can obtain the diploma and internship teacher qualification; after 2 years of education internship and teaching practice, I will continue to take the second national exam. Only those who pass can obtain the national teacher qualification certificate. This method of teacher qualification assessment in Germany is similar to the training of normal students in China, both of which need to accept the learning and teaching practice of professional knowledge in related disciplines, but it appears more rigorous in the process.

\section{SUGGESTIONS ON THE REFORM OF TEACHER QUALIFICATION} EXAMINATION IN CHINA

\section{A. Clarify the Design Idea of the National Examination System and Construct the Open Education System based on the Specialty}

First of all, we should firmly establish the specialization is the core of the education system of teachers. Teacher professionalization is the common goal of teacher career development in today's world. The establishment of professional teacher education system is the core embodiment of modern teacher education. 'to cultivate professional teachers, we should first establish a professional teacher education system, which is realized by the professional education under the condition of modern university system, namely the professional discipline system of teacher education. [8] Secondly, the fundamental goal of establishing the open teacher education system should also be the professional development of teachers. That is to say, professionalism and openness are not binary opposites, the purpose of openness is specialty, and openness should be a kind of professional openness, rather than the current openness that neglects the cultivation of professionalism of candidates.

\section{B. Refine the Evaluation Standards of Each Link, Improve the Reliability of Appraisers, and Improve the Quality of National Examination}

In the process of growing up as a teacher, normal students have to go through the process from learning to thinking to doing, no matter from concept or behavior. The process of learning is mainly the accumulation of knowledge. The process of thinking is mainly the recognition and establishment of relevant concepts. This practical ability is reflected in the practice process of normal university students. The written test of the national examination mainly assesses the thinking ability of the examinees. The interview mainly assesses the examinees' teaching ability and the examinees' moral level. In both the written test and the interview, the standards of each part of the national examination should be specified and corresponding scoring rules should be issued. The evaluation criteria should be further refined to ensure that the evaluator has a high reliability in the evaluation process.

\section{Rich Certification Materials, the Establishment of Authenticity and Practicality of the Combination of Archives Bag Certification System}

The education teaching practice ability and education practice experience of the prospective teacher are very important. Candidates can be required to provide education practice proof materials for more than one semester. The proof material requires recording all kinds of performances of examinees in the practice of education by the way of the file bag. These performances should have the authenticity of relevant references, which cannot be related to relatives or friends of examinees. The portfolio can be recorded and assessed from several aspects, such as teacher's moral experience, teaching practice, class management practice and teaching and research practice. The teacher qualification certification department shall organize relevant experts to conduct selective examination on the authenticity and practicality of the materials submitted by each candidate. Once any false materials are found, the certification shall not be granted.

\section{CONCLUSION}

To sum up, the national examination of teacher certification is a key measure to build a professional and excellent teacher team in China. From the pilot to the full implementation process, the above problems of openness, professionalism, fairness and differences are reflected in both the system design level and the policy implementation level. Accordingly, it should be solved from the aspects of system design and policy implementation so as to further improve the national examination policy, maximize its function and realize the original intention of the national examination policy.

It has been more than ten years since the teacher qualification certificate system was promulgated and implemented around 2000 and the teacher education went open. However, it is still far from being truly "open" whether from the construction of the system or from the composition of teachers' education subject. However, the reform of teacher certification system has released a strong signal: the management level is determined to promote the qualitative leap of the opening of teacher education, that is, to guide the self-adjustment of teacher education subject in the system step by step.

In the future, the scale reduction and level improvement of normal education can be synchronized to ensure the high-level development of normal education and gradually transform to the wisdom and function platform integrating education research, especially education professional development research and high-level training. In this way, it can not only provide intelligent support and platform support for the opening of teachers' education, but also objectively promote 
the diversified process of teachers education subjects. In the long run, the scale contraction, level improvement and functional construction of teacher training education is a basic trend.

\section{REFERENCE}

[1] Chunlan Liu, Youxun zheng. Research on the false growth of teachers under the teacher certification system [J]. Management of Modern Education, 2012, (01): 96-99. (In Chinese)

[2] Shiqiong Jian, Longfeng Ran. Reality contradictions and system perfection in the practice of teacher certification "national examination" [J]. Education Science, 2017 (05) : 52-56. (In Chinese)

[3] Albers, P. 2002. "Praxis II and African American Teacher Gandidates (Or, is Everything Black Bad?)." English Education 34 (2002): 105-125.
[4] Yong Chen, Xiuxiu Bao, Junting Tang. Experience and inspiration of the development of teacher qualification system in primary and secondary schools -- a case study of the us, Germany, Britain and Japan [J]. Foreign Primary and Secondary Schools Education, 2018 (06) :67-71. (In Chinese)

[5] Guoyong Hu. Reform of Japanese teacher education system [J]. Shanghai Education, 2007 (5A) : 40-42. (In Chinese)

[6] Yong ming Chen. Comparative study on reform of international teachers education [M]. Beijing: People's Education Press, 2001.236-243. (In Chinese)

[7] Chenyin Zhong. Reform and dilemma of Japan's teacher certification renewal system [J]. Teacher Education Research, 2009 (21) : 77-80. (In Chinese)

[8] Xudong Zhu. Construction of education system for modern teachers in China [J]. Journal of Beijing Normal University (Social Science Edition), 2007 (04) :15-20. (In Chinese) 